\title{
Kepadatan Populasi Hama Utama Pada 2 Varietas Tanaman Jagung Di Kecamatan Malangke Kabupaten Luwu Utara
}

\author{
Nining Triani Thamrin, Eka Sudartik
}

Program Studi Agroteknologi Fakultas Pertanian Universitas Cokroaminoto Palopo

*Email : niningtriani1606@gmail.com

\begin{abstract}
Abstrak
Rendahnya produksi tanaman jagung di Indonesia disebabkan oleh beberapa faktor salah satunya adalah serangan hama yang menyerang tanaman jagung yang dapat menurunkan kualitas dan kuantitas tanaman jagung, di pertanaman dijumpai beragam jenis hama yang menyerang tanaman jagung dan dilaporkan terdapat 70 jenis hama. Penelitian bertujuan untuk mengetahui kepadatan populasi hama utama pada 2 varietas tanaman jagung di Kecamatan Malangke Kabupaten Luwu Utara. Penelitian ini dilaksanakan di Desa Pembuniang dan Desa Cenning Kecamatan Malangke Kabupaten Luwu Utara yang dimulai pada bulan Juli -Oktober 2019, dengan menggunakan 2 jenis varietas tanaman jagung yakni Varietas Sumo dan Varietas Bonanza. Hasil penelitian menunjukkan bahwa ditunjukkan bahwa tanaman jagung Varietas Sumo dijumpai hama Spodoptera litura (3.22 ekor), Ostrinia furnacalis (2.11 ekor) dan Helicoverpa armigera (1.44 ekor) dan pada Varietas Bonanza ditemukan hama Spodoptera litura (2.44 ekor), Ostrinia furnacalis (0.77 ekor) dan Helicoverpa armigera (0.67 ekor), hal ini dikarenakan tersedianya peruntukan makanan secara terus menerus yang menjadi tanaman inang utama dari ketiga hama tersebut.
\end{abstract}

Keywords : hama, jagung, varietas, sumo dan bonanza.

\section{Pendahuluan}

Tanaman jagung (Zea mays) merupakan salah satu komoditas pangan unggulan yang memiliki prospek yang baik untuk pemenuhan konsumsi pangan nasional serta sebagai sumber pendapatan petani. Dalam kehidupan sehari-hari tanaman jagung paling banyak pemanfaatannya diantaranya jagung dijadikan sebagai bahan untuk industri olahan pangan, bahan industri pakan serta dijadikan sebagai bahan tanaman atau benih. Selain itu tanaman jagung memiliki kandungan dan beberapa zat yang bermanfaat bagi kesehatan. Dengan banyaknya manfaat dan nilai ekonomi tinggi, maka komoditas ini menjadi salah satu komoditas pokok Indonesia. Hal ini mengakibatkan bahwa permintaan akan kebutuhan jagung di masyarakat semakin meningkat. Namun rendahnya produksi jagung menjadikan kebutuhan masyarakat belum terpenuhi.

Rendahnya produksi jagung disebabkan oleh beberapa faktor diantaranya faktor fisik dan faktor biologis meliputi adanya serangan OPT yang menyerang tanaman jagung. Organisme pengganggu tanaman (OPT) adalah setiap organisme yang dapat mengganggu pertumbuhan dan atau perkembangan tanaman sehingga tanaman menjadi rusak, pertumbuhannya terhambat, dan atau mati. UU No. 12 tahun 1992 tentang Sistem Budidaya Tanaman menyatakan bahwa "Organisme Pengganggu Tanaman (OPT) adalah "Semua Organisme yang dapat merusak, mengganggu kehidupan atau menyebabkan kematian tumbuhan"(Sembel, 2012).

Di Indonesia sekitar 70 jenis serangga hama telah dilaporkan menyerang tanaman jagung. Di pertanaman jagung ada beberapa jenis hama yang diantaranya berstatus penting yaitu lalat bibit
(Atherigona sp.), ulat tanah (Agrothis sp.), lundi/uret (Phylophaga hellen), penggerek batang jagung (Ostrinia furnacalis), ulat grayak (Spodoptera litura, Mythimna sp.), penggerek tongkol (Helicoverpa armigera), dan wereng jagung (Peregrinus maydis). Adanya serangan hama menjadi kendala dalam proses budidaya tanaman jagung.

Tanaman jagung yang paling banyak dibudidayakan adalah jagung manis dan jagung pakan ternak. Rondo, dkk (2018) menyatakan bahwa dinamika hama utama dan penyakit pada tanaman jagung manis dan jagung pakan sangat dipengaruhi oleh stadia pertumbuhan tanaman serta pertumbuhan penyakit juga semakin meningkat seiring pertumbuhan tanaman. Fase pertumbuhan tanaman jagung dapat dibagi menjadi lima fase pertumbuhan, yang dimana dari sekian jenis serangga yang menjadi hama pada tanaman jagung, ada spesies yang menyerang hanya pada satu fase tertentu bahkan ada yang menyerang hampir setiap fase pertumbuhan. Sebagai contoh diantaranya adalah hama penggerek batang Ostrinia furnacalis dapat menyerang setiap fase pertumbuhan tanaman dan dapat menyebabkan kehilangan hasil mencapai $80 \%$, ulat grayak juga dapat menyerang seluruh stadia pertumbuhan tanaman jagung.

Penelitian bertujuan untuk mengetahui kepadatan populasi hama utama pada 2 varietas tanaman jagung di Kecamatan Malangke Kabupaten Luwu Utara. 


\section{Metode Penelitian}

Penelitian ini akan dilaksanakan pada bulan Juli Oktober 2019 di Kecamatan Malangke Kabupaten Luwu Utara Bahan-bahan yang akan digunakan dalam penelitian ini adalahtanaman jagung pakan ternak (Varietas Sumo), tanaman jagung manis (Varietas Bonanza), plastik c-tik, alkohol, bambu dan kantong plastik. Alat yang akan digunakan dalam penelitian ini adalah kaca pembesar, hand tally counter, panduan identifikasi serangga, jaring serangga, killing botol, botol koleksi serangga, gunting, sprayer, meteran, kamera dan alat tulis.

\section{Prosedur Kerja}

Penelitian ini dilaksanakan di lahan jagung milik petani di Kecamatan Malangke yang terdiri dari dua lokasi yaitu Desa Pembuniang dan Desa Cenning. Setiap lokasi diambil sampel petak diagonal dengan luas $3 \mathrm{~m} \times 3 \mathrm{~m}$ untuk masing-masing varietas.

\section{Pengambilan sampel}

Pengambilan sampel hama dilakukan pada sore hari dengan menggunakan jaring serangga dan dengan cara penyapuan 10 kali ayunan ganda pada sampel petak lahan jagung untuk masing-masing varietas yang telah ditentukan. Pengambilan sampel ini dilakukan tiga kali ulangan. Hama yang terjaring dimasukkan ke dalam kiliing botol yang berisi alkohol dan kemudian diamati dan dilakukan perhitungan jumlah individu.

\section{Pengamatan}

Pengamatan dilakukan sebanyak 9 kali dan pengambilan data dilakukan secara visual

\section{Hasil dan Pembahasan}

Tabel 1. Kepadatan populasi hama pada varietas Sumo tanaman jagung di Desa Pembuniang Kecamatan Malangke Kabupaten Luwu Utara

\begin{tabular}{cccc}
\hline \multirow{2}{*}{$\begin{array}{c}\text { Populasi } \\
\text { hama/minggu } \\
(\mathrm{mst})\end{array}$} & \multicolumn{3}{c}{ Jenis dan Jumlah Hama (ekor) } \\
\cline { 2 - 4 } & $\begin{array}{l}\text { Spodoptera } \\
\text { litura }\end{array}$ & $\begin{array}{l}\text { Ostrinia } \\
\text { furnacalis }\end{array}$ & $\begin{array}{c}\text { Helicoverpa } \\
\text { armigera }\end{array}$ \\
\hline I & 2 & 0 & 0 \\
II & 2 & 2 & 0 \\
III & 2 & 2 & 0 \\
IV & 3 & 3 & 0 \\
V & 5 & 4 & 0 \\
VI & 5 & 3 & 2 \\
VII & 5 & 2 & 4 \\
VIII & 3 & 2 & 4 \\
IX & 2 & 1 & 3 \\
\hline Total & 29 & 19 & 13 \\
\hline Rata-rata & 3.22 & 2.11 & 1.44 \\
\hline
\end{tabular}

Sumber : Data primer setelah diolah (2019)
Tabel 2. Kepadatan populasi hama pada varietas Bonanza tanaman jagung di Desa Cenning Kecamatan Malangke Kabupaten Luwu Utara

\begin{tabular}{cccc}
\hline \multirow{2}{*}{$\begin{array}{c}\text { Populasi } \\
\text { Seranga/Minggu } \\
\text { (ekor) }\end{array}$} & \multicolumn{3}{c}{ Jenis dan Jumlah Hama (ekor) } \\
\cline { 2 - 4 } & $\begin{array}{c}\text { Spodoptera } \\
\text { litura }\end{array}$ & $\begin{array}{l}\text { Ostrinia } \\
\text { furnachalis }\end{array}$ & $\begin{array}{c}\text { Helicoverpa } \\
\text { armigera }\end{array}$ \\
\hline I & 1 & 0 & 0 \\
II & 2 & 0 & 0 \\
III & 2 & 0 & 0 \\
IV & 2 & 2 & 0 \\
V & 5 & 2 & 0 \\
VI & 5 & 2 & 0 \\
VII & 3 & 1 & 2 \\
VIII & 1 & 0 & 2 \\
IX & 1 & 0 & 2 \\
\hline Total & 22 & 7 & 6 \\
\hline Rata-rata & 2.44 & 0.77 & 0.67 \\
\hline
\end{tabular}

Sumber : Data primer setelah diolah (2019)

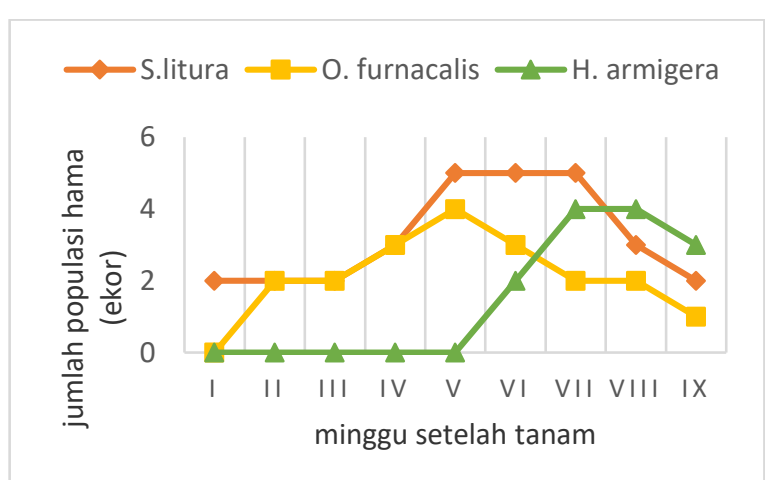

Gambar 1. Populasi Hama Utama pada Tanaman Jagung Varietas Sumo

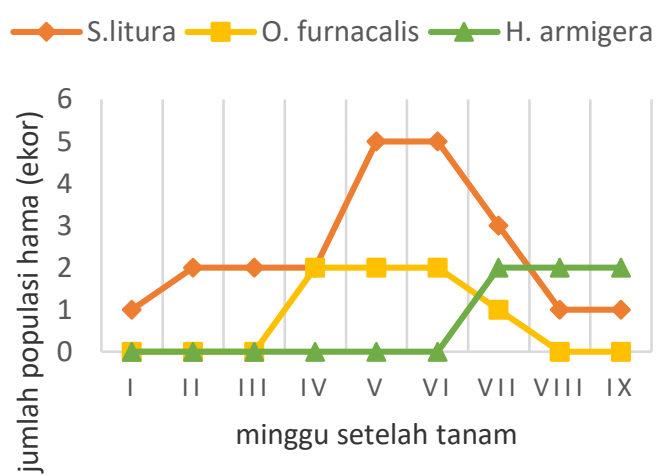

Gambar 2. Populasi Hama Utama pada Tanaman Jagung Varietas Bonanza

Jenis hama yang ditemukan dari pertanaman jagung varietas sumo dan varietas bonanza pada di Desa Pembuniang dan Desa Cenning Kecamatan Malangke bervariasi dari tiap jenisnya. Dari tabel 1 terlihat bahwa hama S.litura menunjukkan populasi tertinggi 3.22 ekor pada varietas sumo dan 2.44 ekor untuk varietas bonanza. Populasi S.litura di pada kedua desa di Kecamatan Malangke tinggi disebabkan karena hama ini 
menyerang hampir di semua fase pertumbuhan, jadi ketersediaan hama ini terus menerus ada pada pertanaman dikarenakan tersedianya tanaman inang secara terus menerus dimana petani setempat membudidayakan tanaman jagung secara terus menerus tanpa melakukan pergiliran tanaman untuk memutus rantai makanan dari hama tanaman jagung. Secara visual gejala serangan S.litura yang ditemui dilapangan yakni larva yang berukuran kecil menyerang tanaman jagung dengan memakan bagian daun. Meninggalkan sisa-sisa bagian atas epidermis daun, transparan dan tinggal tulang-tulang daun (Tenrirawe dan Talanca dalam Rondo, dkk 2016). Surtikanti (2008) menambahkan bahwa serangan S.litura pada tanaman muda dapat menghambat pertumbuhan tanaman bahkan dapat mematikan tanaman. Serangan berat pada pertanaman dapat mengakibatkan tinggal tulang-tulang daun saja.

Pengamatan jumlah populasi terbanyak kedua yaitu hama Ostrinia furnacalis dengan rata-rata 2.11 ekor pada varietas sumo dan 0.77 ekor pada varietas bonanza. Hal ini dikarenakan jangkauan makan dari hama ini sangat besar sehingga sangat sesuai dengan peruntukan makanan O.furnacalis . Hama ini mempunyai karakteristik kerusakan membuat lubang kecil pada daun dan membuat lubang gorokan pada batang. Srikanti (2008) menambahkan bahwa ada pula yang langsung menggerek tulang daun

yang telah terbuka, kemudian menuju batang dan menggerek batang tersebut serta membentuk lorong mengarah ke atas. Setelah sampai dibuku bagian atas, ulat segera turun kebuku bagian bawah. Ulat berpupa di dalam batang.

Hama Helicoverpa armigera merupakan jumlah populasi terendah yang dijumpai di pertanaman jagung pada kedua varietas dengan rata-rata 1.44 ekor untuk varietas sumo dan 0.67 ekor untuk varietas bonanza. Populasi ini didukung oleh ketersediaan buah jagung yang sesuai peruntukkan makanannya bagi hama ini. Gejala serangan yang ditunjukkan di lapangan dengan memakan biji jagung sehingga dapat menurunkan kualitas dan kuantitas pada tongkol jagung. Selain itu hama ini dapat menyerang tanaman muda, terutama pada pucuk atau malai yang. dapat mengakibatkan tidak terbentuknya bunga jantan, berkurangnya hasil dan bahkan tanaman dapat mati (Sparks and Mitchell dalam Baco dan Tandiabang, 1998)

\section{Kesimpulan}

Kepadatan populasi hama utama pada 2 varietas tanaman jagung ditunjukkan pada Varietas Sumo yakni hama Spodoptera litura (3.22 ekor), Ostrinia furnacalis (2.11 ekor) dan Helicoverpa armigera (1.44 ekor) dan pada Varietas Bonanza dijumpai hama Spodoptera litura (2.44 ekor), Ostrinia furnacalis (0.77 ekor) dan Helicoverpa armigera (0.67 ekor), hal ini dikarenakan tersedianya peruntukan makanan secara terus menerus yang menjadi tanaman inang utama dari ketiga hama tersebut.

\section{Ucapan Terima Kasih}

Ucapan terimakasih penulis sampaikan kepada Universitas Cokroaminoto Palopo sebagai pemberi dana hibah penelitian.

\section{Daftar Pustaka}

Baco, D. and J. Tandiabang. 1998. Hama Utama Jagung dan Pengendaliannya. pp. 185-204. Badan Penelitian dan Pengembangan Pertanian. Diakses pada tanggal 15 Februari 2019.

Dowswell, C.R. R.L.Paliwal, and R. P.Cantrell. 1996. Maize in The Third World.

Westview Press.

Irriany, Yasin, dan Andi Takdir. 2000. Asal, Sejarah, Evolusi dan Taksonomi Tanaman Jagung. Balai Penelitian Tanaman Serealia, Maros. Diakses pada tanggal 15 Februari 2019.

Nonci, N., J. Tandiabang, Masmawati, dan A. Muis. 1996. Kehilangan Hasil Oleh Penggerek Jagung O. furnacalis pada Berbagai Stadia Tanaman Jagung. Hasil Penelitian Hama/Penyakit 1995/1996. Balitjas Maros. pp. 27-33. Diakses pada tanggal 18 Februari 2019.

Rondo. 2016. Dinamika Populasi Hama dan Penyakit Utama Tanaman Jagung Manis (Zea mays saccharata Sturt) pada Lahan Basah dengan Sistem Budidaya Konvensional serta Pengaruhnya terhadap Hasil di Denpasar-Bali. Jurnal Agrotop, 6 (2): 128-136. Diakses pada tanggal 15 Februari 2019.

Sembel, D. T., 2012. Dasar-Dasar Perlindungan Tanaman. Fakultas Pertanian UNSRAT Manado. Diakses pada tanggal 18Februari 2019.

Suto, T. and Y. Yoshida. 1956. Characteristics of theOoriental Maize. In H.Kihara, ed. Land and crops of Nepal Himalaya, vol. 2, p. 375-530. Kyoto, Japan, Fauna and Flora Res. Soc. Kyoto University.

Surtikanti. 2008. Hama dan Penyakit Tanaman Jagung dan Pengendaliannya. Balai Penelitian Tanaman Serealia 